\title{
Hysterectomy for primary gynaecological malignancies in a non-cancer centre: prevalence, indications and surgical outcomes at a tertiary hospital in Port-Harcourt, Nigeria: a six-year review
}

\author{
Peter A. Awoyesuku*, Ngozi J. Kwosah, Dickson H. John, Simeon C. Amadi
}

Department of Obstetrics and Gynaecology, Rivers State University Teaching Hospital, 6-8 Harley Street, Old G.R.A, Port-Harcourt, Rivers State, Nigeria

Received: 18 September 2021

Revised: 18 October 2021

Accepted: 19 October 2021

\section{*Correspondence:}

Dr. Peter A Awoyesuku,

E-mail: pawoyesuku@yahoo.co.uk

Copyright: () the author(s), publisher and licensee Medip Academy. This is an open-access article distributed under the terms of the Creative Commons Attribution Non-Commercial License, which permits unrestricted non-commercial use, distribution, and reproduction in any medium, provided the original work is properly cited.

\begin{abstract}
Background: Gynaecological malignancies continue to be an important public health problem globally and are among the leading causes of morbidity and cancer-related deaths worldwide. In developing countries there is poor awareness and late presentation, and specialized cancer treatment centers are few, necessitating the gynaecologists at the tertiary hospitals to render surgical care for some cancer patients. The objective of the study was to determine the prevalence, indications, and surgical outcome of hysterectomy for primary gynaecological malignancies and assess the associated factors.

Methods: This was a retrospective review of hysterectomies performed between March 2015 and February 2021. Data were obtained from operating theater and gynaecological ward records. Information on age, parity, indication, length of surgery, blood loss and any blood transfusion, post-operative complication, and mortality, were extracted. Data were analyzed using Statistical package for social sciences (SPSS) version 20.

Results: Of 1240 major gynaecological surgeries, 26 were hysterectomies for malignant conditions giving a prevalence of $2.1 \%$. Commonest indication was Endometrial cancer $16(61.5 \%)$, followed by cervical cancer $3(11.5 \%)$ and ovarian malignancy $3(11.5 \%)$. There was a significant relationship between age $(\mathrm{p}=0.027)$ with the indications for hysterectomy. Commonest complication was anaemia $6(23.1 \%)$ and wound sepsis 5 (19.2\%). Anaemia was significantly associated with duration of surgery $(\mathrm{p}=0.004)$ and estimated blood loss $(\mathrm{p}=0.005)$.

Conclusions: The prevalence of $2.1 \%$ for a non-cancer center is a fair contribution to efforts at caring for cancer patients. All surgeries were simple TAH $\pm \mathrm{BSO}$ and more than half were done for endometrial cancer. Further training of cancer surgeons and establishment of a Cancer Centre in the State is needed.
\end{abstract}

Keywords: Gynaecological malignancies, Hysterectomy, Endometrial cancer, Cervical cancer, Ovarian cancer, Choriocarcinoma

\section{INTRODUCTION}

Gynaecological malignancies comprise of several tumours with different epidemiology, pathology, and treatment strategies. Gynaecological malignancies include cancers of the ovary, fallopian tubes, uterine body, cervix, vagina, and vulva as well as choriocarcinoma which primarily come under the care of gynaecologists, but excludes breast cancer because it comes under the specialty of general surgery in most developing countries. ${ }^{1}$ For the past three decades the sub-specialty of gynaecological oncology has been recognized with emphasis on expert multiprofessional teamwork as the best model for delivering high quality care, in the framework of a Gynaecological 
Cancer Centre with surrounding Associate Units. ${ }^{1,2}$ However, because of the huge funding gap in developing countries compared to developed countries, these centers are few and, where they exist, they are located far away from the average patient, necessitating the gynaecologists at the tertiary hospitals to continue to render surgical care for some cancer patients. ${ }^{3}$

Gynaecological malignancies continue to be an important public health problem globally and are among the leading causes of morbidity and cancer-related deaths worldwide, particularly in the developing countries where there is poor awareness and late presentation. The burden of gynaecological cancers in the developing countries is huge, accounting for $25 \%$ of all new cancers diagnosed among women aged up to 65 years compared to $16 \%$ in the developed world. ${ }^{4}$ A 2009 report of global estimates for new cases of the commonest gynaecological cancers including cervical, corpus and ovarian cancer, revealed that developing countries accounted for 820,265 cases $(77.7 \%)$ of global cases. ${ }^{3}$ This constituted $12.1 \%$ of the 6.8 million cases of cancer in developing countries. ${ }^{1,3}$

Therapeutic interventions for gynaecological cancers include surgery, chemotherapy, and radiotherapy, with combination modalities often required. Surgery is the oldest therapeutic modality consistently applied in the treatment of gynaecological malignancies, though the actual operations vary considerably among different therapists and the procedures employed are quite different for the different organ sites. ${ }^{5}$ Hysterectomy is a major gynaecological operation for removal of the body of the uterus with or without the cervix and adnexal structures for therapeutic purpose. ${ }^{6}$ Hysterectomy is employed in the management of the commonest gynaecological cancers of the cervix, ovary and corpus as well as choriocarcinoma and these will be the focus of this review.

Cervical cancer is the commonest gynaecological malignancy in developing countries where organized screening programmes do not exist. ${ }^{3,7}$ The standard management of cervical cancer has been established for many years. Disease confined to the cervix, stage (Ia) or microinvasive disease, is associated with a negligible incidence of lymph node metastasis and can be managed by a simple total hysterectomy, where retention of fertility is not desired. ${ }^{8}$ The classic operation for cervical cancer (stage Ib or frankly invasive disease) is called radical hysterectomy with pelvic lymphadenectomy. ${ }^{5}$ This stage can also be managed with radiotherapy (external beam radiation followed by brachytherapy). ${ }^{8}$ However, it should be remembered that the cure rate for early cervical cancer (stage I and II) is the same whether treatment is by surgery or radiation therapy. ${ }^{5}$ For advanced cervical cancer, which may range from parametrial invasion to a pelvis frozen with tumour extending to both pelvic side walls, management is by external beam radiation combined with brachytherapy. ${ }^{8}$
Ovarian cancer is the second commonest gynaecological malignancy in developing countries. ${ }^{9}$ It accounts for $18.8 \%$ of all gynaecological cancers in developing countries and $28.7 \%$ in developed countries. ${ }^{9}$ It has been accepted for a long time that the primary treatment for ovarian cancer should begin with surgery in the form of maximum cytoreduction. ${ }^{8}$ A laparotomy with total hysterectomy (TAH) and bilateral salpingo-oophorectomy (BSO) is usually performed, which may be followed with adjuvant chemotherapy. Only by a proper staging operation, in which all areas in the abdomen that might be potential sites for a metastasis are sampled, can one rule out such metastasis and prove that the cancer is confined to the ovary, reducing the requirement for aggressive adjuvant therapy in early-stage cancer. ${ }^{5}$

Endometrial cancer is commoner in developed countries than in developing countries. ${ }^{10}$ More than $90 \%$ occur in women aged 50 years and above. ${ }^{9}$ It has a more favourable prognosis than ovarian and cervical cancers with a 5-year survival rates around $70 \%$ in developing countries. ${ }^{9}$ The traditional treatment has been $\mathrm{TAH}$ and $\mathrm{BSO}$, and because the vast majority of endometrial cancers are diagnosed early in their course, as a result of generally presenting early with postmenopausal bleeding, this treatment has been highly successful. ${ }^{5,8}$ Adjuvant radiotherapy is used for poorly differentiated disease with deep myometrial invasion. ${ }^{8}$ A transvaginal pelvic ultrasound or preoperative MRI now offers an excellent means of assessing tumour depth and local extent.

Choriocarcinoma represents $0.6 \%$ of all gynaecological malignancies. Approximately 5800 cases occurred worldwide in 2002 out of which 5400 (96.4\%) occurred in developing countries. ${ }^{9}$ Choriocarcinoma is an uncommon malignant neoplasm, which can be either gestational or non-gestational in origin. Distinction of these subtypes has prognostic and therapeutic implications. ${ }^{11}$ The cornerstone of treatment is chemotherapy but in cases when massive haemorrhage occurs, life-saving hysterectomy should be performed. ${ }^{12,13}$ Choriocarcinoma is a highly chemosensitive tumor. The cure rate, even for metastatic choriocarcinoma, is around 90-95\%. ${ }^{14,15}$ Hysterectomy may play a primary role in the management of nonmetastatic or low-risk metastatic gestational trophoblastic disease. It is also essential to perform surgery in the management of chemo-resistant tumours. ${ }^{16}$

Age and parity affect the incidence of gynaecological malignancies. Endometrial and ovarian cancers occur later in reproductive life than cervical cancers and choriocarcinoma seen earlier, commonly in premenopausal or perimenopausal women. ${ }^{17,18}$ Women of high parity have relatively low risk of developing endometrial cancer and it is known that pregnancy is protective against ovarian cancer, while multiparity is associated with increased risk of development of cervical carcinoma. ${ }^{17,18}$ 
There is paucity of data on hysterectomy for primary gynaecological malignancies in our environment. It became necessary to determine the prevalence, indications, surgical outcomes, and associated factors to serve as baseline for further research. This study therefore sought to determine the prevalence and indications for hysterectomy for primary gynaecological malignancies at the RSUTH and to evaluate the surgical outcome and assess the associated factors. Findings from this study will serve to establish a baseline information for the pattern of hysterectomies for primary gynaecological malignancies in Nigeria.

\section{METHODS}

This study was conducted at the gynaecological ward of RSUTH, a tertiary hospital owned and funded by the Government of Rivers State of Nigeria. The hospital provides gynaecological consultations and surgeries to women referred from other centres, as well as patients registered with the hospital. The hospital is well equipped and has availability of qualified team comprising Gynaecologists and Anaesthetists. There is availability of laboratory and blood bank services in the hospital.

A retrospective descriptive study over a six-year period, March 2015 to February 2021, was carried out. The study population was all women who had hysterectomy for malignant gynaecological indications at the gynaecological ward of the RSUTH. All cases of gynaecological hysterectomy for malignant indications performed from 1st March 2015 to 28th February 2021, with complete records were included. Those with incomplete data were excluded.

Data was retrieved from the gynaecological ward records, the theatre registers and case folders of all the patients who had gynaecological hysterectomy for malignant indications within the study period, using a structured proforma. Information on maternal age, parity, indication, type, and length of surgery, estimated blood loss, blood transfusion, intraoperative and postoperative complication, and mortality, were extracted.

Coded data were entered into Excel spreadsheet and exported to Statistical package for social sciences (SPSS) version 20 for statistical analysis. Categorical measurements were given as numbers and percentages, and numerical measurements as mean and standard deviation. The Chi-square test or Fisher exact test and ANOVA test were used for statistical analysis of noncontinuous and continuous variables as appropriate and statistical significance was set at $\mathrm{p}<0.05$.

\section{RESULTS}

During the six-year study period, a total of 1240 major gynaecological surgeries were carried out, of which 26 were hysterectomies for malignant gynaecological conditions, giving a prevalence of $2.1 \%$. The distribution of type of hysterectomies, as shown in Figure 1, revealed $11(42.3 \%)$ were TAH alone, while $15(57.7 \%)$ were TAH with BSO.

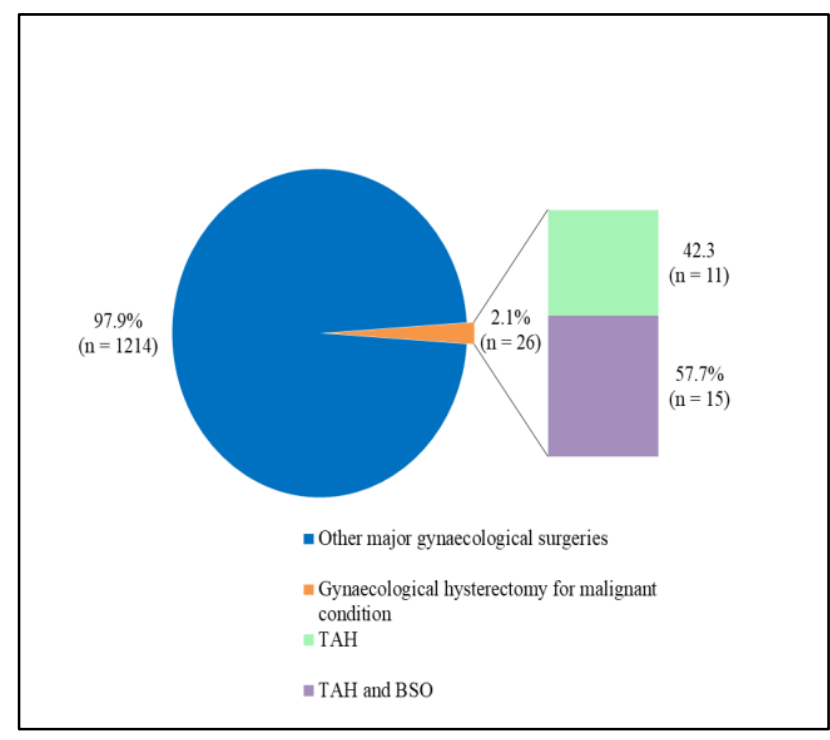

Figure 1: Prevalence of hysterectomy for malignant conditions among women at the RSUTH.

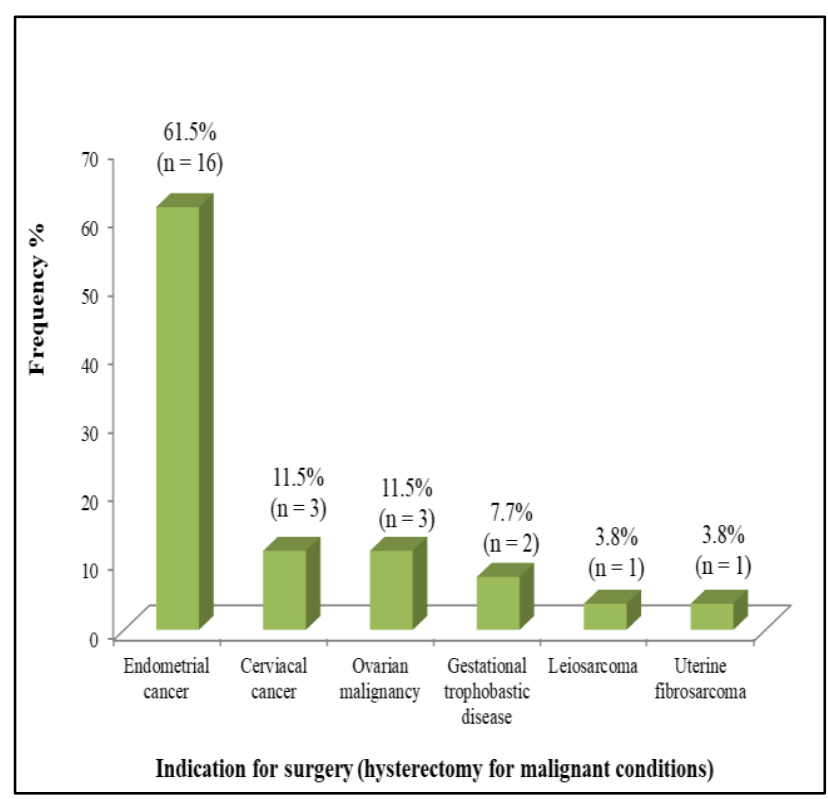

Figure 2: Indication for hysterectomy for malignant conditions among women at the RSUTH.

The mean age of the study population \pm SD was $53.77 \pm 10.10$ years, with median of 52 years and age range of 37-71 years. The median parity was 3 , with a range of $0-8$. Majority of the women, $9(34.6 \%)$ were in the age group of 41-50 years, but those 51 years and above made up $15(57.7 \%)$. Majority of the women $21(80.8 \%)$ were multiparous in the para 2-4 group. The distribution of the maternal characteristics is shown in Table 1. There was no significant association between age $(\mathrm{p}=0.161)$ and parity $(p=0.494)$ with the type of hysterectomy performed. 
Table 1: Maternal characteristics of women who had hysterectomy for gynaecological malignancy at the

\section{RSUTH.}

\begin{tabular}{|lll|}
\hline Variables & Frequency & Percentage \\
\hline Age category & & \\
\hline$\leq 40$ years & 2 & 7.7 \\
\hline 41-50 years & 9 & 34.6 \\
\hline 51-60 years & 7 & 26.9 \\
\hline$>60$ years & 8 & 30.8 \\
\hline Parity & & \\
\hline Para 0 & 2 & 7.7 \\
\hline Para 2 & 5 & 19.2 \\
\hline Para 3 & 12 & 46.2 \\
\hline Para 4 & 4 & 15.4 \\
\hline Para $\geq 5$ & 3 & 11.5 \\
\hline
\end{tabular}

Figure 2 relates to the indications for hysterectomy in the study population. The commonest indication was Endometrial cancer $16(61.5 \%)$, followed by cervical cancer $3(11.5 \%)$, ovarian malignancy $3(11.5 \%)$, choriocarcinoma $2(7.7 \%)$ and uterine fibrosarcoma 1 (3.8\%). Table 2 shows the relationship between age and parity with the various indications for hysterectomy. There was a statistically significant relationship between age $(\mathrm{p}=0.027)$, but not parity $(\mathrm{p}=0.942)$, with the indications for hysterectomy. Younger women were more likely to have hysterectomy for ovarian malignancy and choriocarcinoma, while older women were more likely to have hysterectomy for endometrial cancer and cervical cancer.

The intraoperative findings were. mean duration of surgery \pm SD of $103.31 \pm 43.33$ minutes, the median was 92.50 minutes, and the range was 55-232 minutes.

Table 2: Relationship between age and parity with indication for hysterectomy for malignant condition among women at the RSUTH.

\begin{tabular}{|c|c|c|c|c|c|c|c|}
\hline \multicolumn{7}{|c|}{ Indication for hysterectomy for malignant conditions } & \multirow[b]{2}{*}{$\begin{array}{l}\text { Total } \\
\text { n }(\%)\end{array}$} \\
\hline Variables & $\begin{array}{l}\text { Endometri } \\
\text { al cancer } \\
\text { n }(\%)\end{array}$ & $\begin{array}{l}\text { Cervical } \\
\text { cancer } \\
n(\%)\end{array}$ & $\begin{array}{l}\text { Ovarian } \\
\text { malignancy } \\
\text { n }(\%)\end{array}$ & $\begin{array}{l}\text { Gestational } \\
\text { trophoblastic } \\
\text { disease } \\
\text { n }(\%)\end{array}$ & $\begin{array}{l}\text { Leiomyos } \\
\text { arcoma } \\
\text { n }(\%)\end{array}$ & $\begin{array}{l}\text { Uterine } \\
\text { fibrosarco } \\
\text { ma n }(\%)\end{array}$ & \\
\hline \multicolumn{8}{|c|}{ Age category } \\
\hline$\leq 40$ years & $0(0.0)$ & $0(0.0)$ & $0(0.0)$ & $2(100.0)$ & $0(0.0)$ & $0(0.0)$ & $\begin{array}{l}2 \\
(100.0)\end{array}$ \\
\hline $41-50$ years & $4(44.4)$ & $1(11.1)$ & $2(22.2)$ & $0(0.0)$ & $1(11.1)$ & $1(11.1)$ & $\begin{array}{l}9 \\
(100.0)\end{array}$ \\
\hline $51-60$ years & $6(85.7)$ & $0(0.0)$ & $1(14.3)$ & $0(0.0)$ & $0(0.0)$ & $0(0.0)$ & $\begin{array}{l}7 \\
(100.0)\end{array}$ \\
\hline$>60$ years & $6(75.0)$ & $2(25.0)$ & $0(0.0)$ & $0(0.0)$ & $0(0.0)$ & $0(0.0)$ & $\begin{array}{l}8 \\
(100.0)\end{array}$ \\
\hline \multicolumn{8}{|c|}{ Fisher's exact test $=20.009 ; \mathrm{p}$ value $=0.027^{*}$} \\
\hline \multicolumn{8}{|c|}{ Parity } \\
\hline Para 0 & $2(100.0)$ & $0(0.0)$ & $0(0.0)$ & $0(0.0)$ & $0(0.0)$ & $0(0.0)$ & $\begin{array}{l}2 \\
(100.0)\end{array}$ \\
\hline Para 2 & $2(40.0)$ & $1(20.0)$ & $1(20.0)$ & $0(0.0)$ & $0(0.0)$ & $1(20.0)$ & $\begin{array}{l}5 \\
(100.0)\end{array}$ \\
\hline Para 3 & $7(58.3)$ & $1(8.3)$ & $1(8.3)$ & $2(16.7)$ & $0(0.0)$ & $1(8.3)$ & $\begin{array}{l}12 \\
(100.0)\end{array}$ \\
\hline Para 4 & $3(75.0)$ & $0(0.0)$ & $1(25.0)$ & $0(0.0)$ & $0(0.0)$ & $0(0.0)$ & $\begin{array}{l}4 \\
(100.0)\end{array}$ \\
\hline Para $\geq 5$ & $2(66.7)$ & $1(33.3)$ & $0(0.0)$ & $0(0.0)$ & $0(0.0)$ & $0(0.0)$ & $\begin{array}{l}3 \\
(100.0)\end{array}$ \\
\hline
\end{tabular}

*Statistically significant $(\mathrm{p}<0.05)$

The mean estimated blood loss \pm SD was $601.92 \pm 129.99$ $\mathrm{ml}$, the median was $600 \mathrm{ml}$, and the range was $400-1000$ ml. Majority of the women had a duration of surgery (DOS) of $<120$ minutes 20 (76.9\%), estimated blood loss (EBL) of $\geq 500 \mathrm{mls} 24(92.3 \%)$ and received blood transfusion $20(76.9 \%)$. A comparison of mean DOS and mean EBL by age and parity of the women (Table 3) revealed no significant association between DOS with age of the women $(\mathrm{p}=0.561)$ and parity $(\mathrm{p}=0.421)$. There was also no significant association between EBL with age $(p=0.665)$ and parity $(p=0.118)$. Table 4 relates to comparison between age and parity of the women with the 
need for blood transfusion, and there was no significant association between blood transfusion and age $(\mathrm{p}=0.385)$ or parity $(\mathrm{p}=0.900)$.

Table 3: Comparison of mean duration of surgery and estimated blood loss by age and parity among women at the RSUTH.

\begin{tabular}{|c|c|c|}
\hline Variables & $\begin{array}{l}\text { Duration of } \\
\text { surgery } \\
\text { (minutes) } \\
\text { Mean } \pm \text { SD }\end{array}$ & $\begin{array}{l}\text { Estimated blood } \\
\text { loss }(\mathrm{ml}) \\
\text { Mean } \pm \text { SD }\end{array}$ \\
\hline \multicolumn{3}{|c|}{ Age category } \\
\hline$\leq 40$ years & $79.50 \pm 9.19$ & $700.00 \pm 141.42$ \\
\hline $\begin{array}{l}41-50 \\
\text { years }\end{array}$ & $103.67 \pm 29.69$ & $577.78 \pm 106.39$ \\
\hline $\begin{array}{l}51-60 \\
\text { years }\end{array}$ & $91.57 \pm 22.36$ & $585.71 \pm 89.97$ \\
\hline \multirow[t]{2}{*}{$>60$ years } & $119.13 \pm 68.35$ & $618.75 \pm 183.10$ \\
\hline & $\begin{array}{l}\text { ANOVA }=0.702 \\
p=0.561\end{array}$ & $\begin{array}{l}\text { ANOVA }=0.532 \\
p=0.665\end{array}$ \\
\hline \multicolumn{3}{|l|}{ Parity } \\
\hline Para 0 & $136.50 \pm 106.77$ & $800.00 \pm 282.84$ \\
\hline Para 2 & $92.40 \pm 23.44$ & $520.00 \pm 83.67$ \\
\hline Para 3 & $97.92 \pm 27.14$ & $612.50 \pm 115.06$ \\
\hline Para 4 & $131.75 \pm 71.68$ & $562.50 \pm 75.00$ \\
\hline \multirow[t]{2}{*}{ Para $\geq 5$} & $83.00 \pm 33.15$ & $616.67 \pm 125.83$ \\
\hline & $\begin{array}{l}\text { ANOVA = } \\
1.018 \\
p=0.421\end{array}$ & $\begin{array}{l}\text { ANOVA }=2.089 \\
p=0.118\end{array}$ \\
\hline
\end{tabular}

Table 4: Relationship between age and parity with blood transfusion among women at the RSUTH.

\begin{tabular}{|c|c|c|c|}
\hline \multicolumn{4}{|c|}{ Blood transfusion } \\
\hline Variables & $\begin{array}{l}\text { Yes } \\
\text { n }(\%)\end{array}$ & $\begin{array}{l}\text { No } \\
\text { n }(\%)\end{array}$ & $\begin{array}{l}\text { Total } \\
\text { n }(\%)\end{array}$ \\
\hline \multicolumn{4}{|c|}{ Age category } \\
\hline$\leq 40$ years & $2(100.0)$ & $0(0.0)$ & $2(100.0)$ \\
\hline $41-50$ years & $5(55.6)$ & $4(44.4)$ & $9(100.0)$ \\
\hline 51-60 years & $6(85.7)$ & $1(14.3)$ & $7(100.0)$ \\
\hline$>60$ years & $7(87.5)$ & $1(12.5)$ & $8(100.0)$ \\
\hline \multicolumn{4}{|c|}{ Fisher's exact test $=2.985 ; \mathrm{p}$-value $=0.385$} \\
\hline \multicolumn{4}{|l|}{ Parity } \\
\hline Para 0 & $2(100.0)$ & $0(0.0)$ & $2(100.0)$ \\
\hline Para 2 & $3(60.0)$ & $2(40.0)$ & $5(100.0)$ \\
\hline Para 3 & $9(75.0)$ & $3(25.0)$ & $12(100.0)$ \\
\hline Para 4 & $3(75.0)$ & $1(25.0)$ & $4(100.0)$ \\
\hline Para $\geq 5$ & $3(100.0)$ & $0(0.0)$ & $3(100.0)$ \\
\hline \multicolumn{4}{|c|}{ Fisher's exact test $=2.078 ; \mathrm{p}$-value $=0.900$} \\
\hline
\end{tabular}

Table 5 relates to the complications from hysterectomy among the study population. The commonest complication was anaemia in $6(23.1 \%)$, followed by wound sepsis in 5 (19.2\%). No intraoperative injury or mortality occurred.
Table 5: Complications from hysterectomy for malignant conditions among women at the RSUTH.

\begin{tabular}{|lll|}
\hline Variables & Frequency & Percentage \\
\hline Anaemia & & \\
\hline Yes & 6 & 23.1 \\
\hline No & 20 & 76.9 \\
\hline Sepsis & & \\
\hline Yes & 5 & 19.2 \\
\hline No & 21 & 80.8 \\
\hline
\end{tabular}

Table 6: Relationship between age and parity with anaemia among women at the RSUTH.

\begin{tabular}{|c|c|c|c|}
\hline \multicolumn{4}{|c|}{ Anaemia } \\
\hline Variables & $\begin{array}{l}\text { Yes } \\
\text { n }(\%)\end{array}$ & $\begin{array}{l}\text { No } \\
\text { n }(\%)\end{array}$ & $\begin{array}{l}\text { Total } \\
\text { n }(\%)\end{array}$ \\
\hline \multicolumn{4}{|c|}{ Age category } \\
\hline$\leq 40$ years & $1(50.0)$ & $1(50.0)$ & $2(100.0)$ \\
\hline $41-50$ years & $2(22.2)$ & $7(77.8)$ & $9(100.0)$ \\
\hline $51-60$ years & $0(0.0)$ & $7(100.0)$ & $7(100.0)$ \\
\hline$>60$ years & $3(37.5)$ & $5(62.5)$ & $8(100.0)$ \\
\hline \multicolumn{4}{|c|}{ Fisher's exact test $=4.104 ; p=0.242$} \\
\hline \multicolumn{4}{|l|}{ Parity } \\
\hline Para 0 & $1(50.0)$ & $1(50.0)$ & $2(100.0)$ \\
\hline Para 2 & $0(0.0)$ & $5(100.0)$ & $5(100.0)$ \\
\hline Para 3 & $4(33.3)$ & $8(66.7)$ & $12(100.0)$ \\
\hline Para 4 & $1(25.0)$ & $3(75.0)$ & $4(100.0)$ \\
\hline Para $\geq 5$ & $0(0.0)$ & $3(100.0)$ & $3(100.0)$ \\
\hline
\end{tabular}

Table 7: Relationship between age and parity with sepsis among women at the RSUTH.

\begin{tabular}{|c|c|c|c|}
\hline \multicolumn{4}{|c|}{ Sepsis } \\
\hline Variables & $\begin{array}{l}\text { Yes } \\
\text { n }(\%)\end{array}$ & $\begin{array}{l}\text { No } \\
\text { n }(\%)\end{array}$ & $\begin{array}{l}\text { Total } \\
\text { n }(\%)\end{array}$ \\
\hline \multicolumn{4}{|c|}{ Age category } \\
\hline$\leq 40$ years & $0(0.0)$ & $2(100.0)$ & $2(100.0)$ \\
\hline $\begin{array}{l}41-50 \\
\text { years }\end{array}$ & $3(33.3)$ & $6(66.7)$ & $9(100.0)$ \\
\hline $\begin{array}{l}51-60 \\
\text { years }\end{array}$ & $1(14.3)$ & $6(85.7)$ & $7(100.0)$ \\
\hline$>60$ years & $1(12.5)$ & $7(87.5)$ & $8(100.0)$ \\
\hline \multicolumn{4}{|c|}{ Fisher's exact test $=1.691 ; \mathrm{p}$-value $=0.720$} \\
\hline \multicolumn{4}{|l|}{ Parity } \\
\hline Para 0 & $1(50.0)$ & $1(50.0)$ & $2(100.0)$ \\
\hline Para 2 & $1(20.0)$ & $4(80.0)$ & $5(100.0)$ \\
\hline Para 3 & $2(16.7)$ & $10(583.3)$ & $12(100.0)$ \\
\hline Para 4 & $0(0.0)$ & $4(100.0)$ & $4(100.0)$ \\
\hline Para $\geq 5$ & $1(33.3)$ & $2(66.7)$ & $3(100.0)$ \\
\hline
\end{tabular}

There was no significant association (Table 6) between the occurrence of anaemia with age $(\mathrm{p}=0.242)$ or parity $(\mathrm{p}=0.477)$ and no significant association (Table 7) between 
the occurrence of sepsis and age $(\mathrm{p}=0.720)$ or parity $(\mathrm{p}=0.598)$. A comparison of the mean DOS and mean EBL by surgical complications among the women is shown in Table 8. There was a significant association between DOS with anaemia $(p=0.004)$ but not sepsis $(p=0.315)$, while EBL was also significantly associated with anaemia $(\mathrm{p}=0.005)$ but not sepsis $(\mathrm{p}=972)$.

Table 8: Comparison of mean duration of surgery and blood estimated loss by surgical complications among women at RSUTH.

\begin{tabular}{|lll|} 
Variables & $\begin{array}{l}\text { Duration of } \\
\text { surgery } \\
\text { (minutes) } \\
\text { Mean } \pm \text { SD }\end{array}$ & $\begin{array}{l}\text { Estimated blood } \\
\text { loss }(\mathrm{ml}) \\
\text { Mean } \pm \text { SD }\end{array}$ \\
\hline Anaemia & & \\
\hline Yes & $145.50 \pm 61.26$ & $725.00 \pm 178.19$ \\
\hline No & $90.65 \pm 27.42$ & $565.00 \pm 87.51$ \\
\hline & $\mathrm{t}=3.176$ & $\mathrm{t}=3.053$ \\
& $\mathrm{p}=0.004^{*}$ & $\mathrm{p}=0.005^{*}$ \\
\hline Sepsis & & \\
\hline Yes & $121.00 \pm 56.45$ & $600.00 \pm 234.52$ \\
\hline No & $99.10 \pm 40.16$ & $602.38 \pm 100.59$ \\
\hline & $\mathrm{t}=1.017$ & $\mathrm{t}=-0.036$ \\
& $\mathrm{p}=0.319$ & $\mathrm{p}=0.972$ \\
\hline
\end{tabular}

*Statistically significant $(\mathrm{p}<0.05)$

\section{DISCUSSION}

The prevalence of hysterectomy for malignant conditions of $2.1 \%$, of all gynaecological surgery appears to be the first report on the subject. Many studies report on the pattern of gynaecological cancers or hysterectomy for benign conditions, but a few that reported on hysterectomies for both benign and malignant conditions were found. An extrapolation from their findings of the prevalence for malignant conditions revealed figures of $0.46 \%, 1.6 \%$, and $2.2 \%$, of all major gynaecological surgeries. These reports are all from tertiary hospitals that are not designated "cancer centers" and the figures reflect the volume of work carried out in these centers. ${ }^{19-21}$

The commonest malignant indication for hysterectomy found in this study was endometrial cancer in $>60 \%$ of the study population. Surgery (TAH \pm BSO) is the mainstay of treatment for endometrial cancer, and around $90 \%$ of women treated by primary surgery have a five-year survival rate of over $70 \% .^{22,23}$ Endometrial cancer rarely develops before menopause, and since it causes abnormal vaginal bleeding, it can usually be diagnosed at an early stage, as was in these patients. A transvaginal pelvic ultrasound can sufficiently be used to accurately determine the extent and depth of the lesion and select cases for hysterectomy that would not need further treatment. ${ }^{24}$

Cervical cancer and ovarian malignancy were responsible for hysterectomy in $11.5 \%$ each in the study population. While cervical cancer and ovarian cancer are the first and second commonest gynaecological malignancies, the patients often present in advanced stages of the disease due to poor uptake of routine screening (cervical cancer) or lack of standard screening (ovarian cancer). ${ }^{10,17}$ Only stage 1a cervical cancer patients are treated with surgery in our center and others are referred to centers that have radiotherapy facilities. Surgery is currently the first intervention used to treat ovarian cancer, but in most women the disease is far too advanced by the time of diagnosis for complete removal of the tumour to be possible. Two of the three patients who had hysterectomy for ovarian cancer subsequently received adjuvant chemotherapy.

Age and parity affect the incidence of gynaecological malignancies. Endometrial and ovarian cancers occur later in reproductive life than cervical cancers and choriocarcinoma seen earlier, commonly in premenopausal or perimenopausal women. ${ }^{17,18}$ In this study younger women were more likely to have hysterectomy for ovarian malignancy and choriocarcinoma, while older women were more likely to have hysterectomy for endometrial cancer and cervical cancer. The higher rate of hysterectomy for cervical cancer in older women and ovarian malignancy in younger women is entirely a reflection of the study population and do not reflect the established age incidences of these cancers.

This was a retrospective review of cases of hysterectomy with patient follow-up limited to what was available in the records which makes it difficult to determine long-term medical and psychological complications. Also, the data collected were from a single institution, and as such the findings cannot be generalized.

\section{CONCLUSION}

The prevalence of hysterectomy for malignant conditions of $2.1 \%$, of all gynaecological surgery during the study period, for a non-cancer center, is a fair contribution to efforts at caring for cancer patients. All surgeries were simple $\mathrm{TAH} \pm \mathrm{BSO}$ as the expertise for complex surgery was lacking, though more than half were done for endometrial cancer, a condition often successfully treated by surgery alone. Further training of cancer surgeons and the establishment of a Cancer Centre in the State is needed.

\section{ACKNOWLEDGEMENTS}

The authors wish to acknowledge the contributions of the interns and resident doctors who voluntarily assisted in retrieving data from case notes and hospital records.

\section{Funding: No funding sources}

Conflict of interest: None declared

Ethical approval: The study was approved by the institutional ethics committee 


\section{REFERENCES}

1. Iyoke CA, Ugwu GO. Burden of gynaecological cancers in developing countries. World J Obstet Gynecol. 2013;2(1):1-7.

2. Anon. A policy framework for commissioning cancer services. A joint Working Group response by the Royal College of Obstetricians and Gynaecologists and the British Gynaecological Cancer Society. London: RCOG Press. 1997.

3. The Economist Intelligence Unit. Breakaway: The global burden of cancer-challenges and opportunities. The Economist. 2009.

4. Ferlay J, Bray F, Norman D, Mathers C, Parkin DM. GLOBOCAN 2008, Cancer incidence and mortality worldwide. International Agency for Research on Cancer. 2008.

5. Cohen CJ. The Role of Surgery in the Treatment of Gynecologic Cancers - A Shifting Paradigm. Business Briefing: US Oncology Review. 2004;2(1):2-4.

6. Howard WJ. Abdominal hysterectomy. In: John AR, Howard WR. editors. Te Linde's Operative Gynecology. 10th ed. Philadelphia; Lippincott Williams and Wilkins. 2008;6:727-33.

7. International Agency for Research on Cancer. GLOBOCAN 2008 Fast stats. Available at: http://www.globocan.iarc.fr/ Accessed on 30 August 302021.

8. Kitchener HC. Progress in the management of solid tumours: Gynaecological cancer. Postgrad Med J. 1999;75:332-8

9. Sankaranarayanan R, Ferlay J. Worldwide burden of gynaecological cancer: the size of the problem. Best Pract Res Clin Obstet Gynaecol. 2006;20:207-25.

10. Fader AN, Arriba LN, Frasure HE, von Gruenigen VE. Endometrial cancer and obesity: epidemiology, biomarkers, prevention and survivorship. Gynecol Oncol. 2009;114:121-7.

11. Savage J, Adams E, Veras E, Murphy KM, Ronnett BM. Choriocarcinoma in women. The American Journal of Surgical Pathology. 2017;41(12):1593606.

12. FLam F. Emergency surgery in gestational trophoblastic tumours. Eur. J. Obstet. Gynecol. Reprod. Biol 1994;55:183.

13. Tse K.Y, Chan KK, Tam KF, Ngan HY. 20-year experience of managing profuse bleeding in gestational trophoblastic disease. J Reprod Med. 2007;52:397.

14. Tomoda Y, Arii Y, Kaseki S, Asai Y, Gotoh S, Suzuki $\mathrm{T}$ et al. Surgical indications in pulmonary metastasis of choriocarcinoma. Cancer. 1980;46:2723.

15. Ishizuka T, Tomoda Y, Kaseki S, Goyo S, Hara T, Kobayashi $\mathrm{T}$ et al. Intracranial metastasis of choriocarcinoma: A clinicopathologic study. Cancer. 1983;52:1896.

16. Lehman E, Gershenson DM, Burke TW, Leveback C, Silva EG, Morris M. Salvage surgery for chemo refractory gestational trophoblastic disease. J. Clin. Oncol. 1994;12:2737.

17. Gabra H, Blagden S. Epithelial Ovarian Cancer. In: Dewhurst's Textbook of Obstetrics and Gynaecology for Postgraduates. Edmonds DK. (Ed) 8th edition. London: John Wiley and Sons Ltd. 760-775.

18. Yakasai IA, Ugwa EA, Otubu J. Gynecological malignancies in Aminu Kano Teaching Hospital Kano: A 3 year review. Nigerian J Clin Pract. 2013;16(1):63-6.

19. Rabiu A, Habib R. Elective abdominal hysterectomy: Appraisal of indications and complications at Aminu Kano Teaching Hospital An 8-year review. Trop J Obstet Gynaecol. 2017;34:224-8.

20. Adenaya OR, Ojo OO, Ade-Onojobi AO. Pattern of Gynaecological Total Abdominal Hysterectomy (TAH) in Abeokuta, Southwest Nigeria; a Five-Year Review. Journal of Medical Science and Clinical Research. 2020;8(5):297-304.

21. Abah MG, Olatunbosun OA. An audit of gynaecological hysterectomies in the university of Uyo teaching hospital: Case for non-descent. International Journal of Clinical Obstetrics and Gynaecology. 2019;3(5):161-5.

22. Hacker NF, Friedlander M. Uterine cancer. In: Berek JS, Hacker NF, editors. Berek and Hacker's Gynecologic Oncology. 6th ed. China: Library of Congress Cataloguing-in-publication Data. 2015;390-442.

23. Berrino F, Sant M, Verdecchia A. editors. Survival of cancer patients in Europe: the EUROCARE study. Lyon: International Agency for Research on Cancer. 1995.

24. Smith-Bindman R, Kerlikowske K, Feldstein VA. Endovaginal ultrasound to exclude endometrial cancer and other endometrial abnormalities. JAMA. 1998;280:1510-7.

Cite this article as: Awoyesuku PA, Kwosah NJ, John DH, Amadi SC. Hysterectomy for primary gynaecological malignancies in a non-cancer centre: prevalence, indications and surgical outcomes at a tertiary hospital in Port-Harcourt, Nigeria: a six-year review. Int J Reprod Contracept Obstet Gynecol 2021;10:4052-8. 